Original Article

\title{
EFFECTIVENESS OF SELF INSTRUCTIONAL MODULE ON KNOWLEDGE OF POST OPERATIVE SELF CARE FOR MOTHERS UNDERGOING ELECTIVE CAESAREAN SECTION IN SELECTED HOSPITALS, MANGALORE
}

\author{
Elizabeth Rajan $^{1} \&$ Sabitha Nayak \\ ${ }^{1}$ Senior Lecturer, Lourdes College of Nursing, Cochin, Kerala \\ ${ }^{2}$ Vice Principal, Nitte Usha Institute of Nursing Sciences, Nitte University, M angalore - 575 018, India. \\ Correspondence : \\ Sabitha Nayak, \\ Vice Principal, Nitte Usha Institute of Nursing Sciences, Nitte University, Paneer, M angalore - 575 018, India. \\ M obile : +919448842698 E-mail: sabitha@ nitte.edu.in
}

\begin{abstract}
:
The study was conducted on Effectiveness of self instructional module on knowledge of post operative self care for mothers undergoing elective caesarean section in selected hospitals, M angalore. The research design was a one group pre test post test design which was a pre experimental research design. 40 mothers undergoing elective caesarean section by purposive sampling.

The pretest knowledge questionnaire was administered to the mothers two days prior to caesarean section, followed by a self instructional module on post operative self care. Post test was conducted after 5 days using the same tool. The collected data were analyzed using descriptive and inferential statistics. The mean knowledge score was 14.98 whereas maximum possible score was 30 . Among the 11 areas, the mean percentage knowledge score in the area of caesarean section and self care was $77.50 \%$ bladder and bowel care was $60 \%$ breast feeding was $58.40 \%$ diet was $52.50 \%$ pain management was $47.50 \%$ post operative complications and home care was $46 \%$ baby care was $44.33 \%$ early ambulation and exercise was $44 \%$ perineal hygiene was $41 \%$ wound care was $40.67 \%$ and deep breathing and coughing was $40.67 \%$.

The 't' value showed significant in the post test ('t' calculated value of pretest and post test knowledge scores $=18.000, p<0.001$ ) which showed that self-instructional module was effective in improving the knowledge of mothers on post operative self care after caesarian section.

There was significant association between the level of knowledge and demographic variables namely age parity, education, occupation, monthly income, exposure to health awareness and history of caesarean section.
\end{abstract}

Keywords: Caesarean section; mothers; post operative self care; self instructional module.

\section{Introduction:}

In philosophy, the woman symbolizes the mother's natural feminine characteristics in the universe. A birth of a child is generally viewed as a time of rejoicing, despite the physical pain and exhaustion experienced by many women during childbirth. Usually pregnancy is a normal pathway. Some

\begin{tabular}{|c|}
\hline Access this article online \\
\hline Quick Response Code \\
\hline
\end{tabular}

go with struggle, yet couldn't achieve normal delivery. Such types of mothers are considered for operative delivery. The ultimate aim is to preserve the life and health of the mother and fetus which is successfully done through the process of caesarean section. ${ }^{1}$

Today, it is one of the most frequently performed surgeries in the world. Caesarean births are more common than most surgeries due to many factors. One factor, of course, is that nearly $50 \%$ of the world population are women, and pregnancy is still a very common condition. However, more important is the fact that a caesarean section may be life saving for the baby, or mother (or both). Caesarean birth is also much safer today than it was a few decades ago. Thus 'caesarean' is not something that should scare, as the ultimate goal is a healthy mother and healthy baby, regardless of the method of delivery. ${ }^{2}$ 


\section{Statement of the Problem}

"Effectiveness of self instructional module on knowledge of post operative self care for mothers undergoing elective caesarean section in selected hospitals, M angalore".

\section{Objectives of the Study}

1. To assess the level of knowledge on post operative self care among mothers undergoing elective caesarean section.

2. To identify the effectiveness of self instructional module in terms of gain in knowledge among mothers undergoing elective caesarean section.

3. To find the association between the pre test level of knowledge on post operative self care with selected demographic variables.

\section{Background of the Study}

Internationally caesarean section rate is on the increase. During the last decade there has been two to three fold rise in the incidence. WHO recommends that the caesarean section rate of $10-15 \%$ should not be exceeded. But the results of National Sentinel caesarean section audit shows that caesarean section rates are high as above $24 \%$ in most of the developed and developing countries. According to the centre for disease control and prevention more than 7 Lakh pregnancies per year go to first time caesarean section. ${ }^{3,4}$

Self care is an integral part of holistic living of one's life. Self care approach is a challenge in post operative period in the health care system. Post operative period after caesarean section is a time of transition during which the mother must care for herself and for her newborn. Educating the mother preoperatively on post operative self care will help them to practice it as early as possible after the delivery; there by improving the self care practices and preventing complications.

\section{Conceptual Framework}

The framework of the study is based on general system theory model developed by Ludwig Von Bretalanffy (1986).General system theory serves as a model for viewing people as interacting components within a boundary that filters the type and rate of exchange with the environment. A system consists of both structural and functional components. A structure refers to the arrangement of the facts at a given time. Function is the process of continuous change in the system as a matter; energy and information are exchanged with the environment. The client is an open system capable of both input and output related to the environmental influences, interacting with the environment by adjusting the environment to itself. The feedback information of environment in response to the system's output is used by the system in adjustment, correlation and accommodation to the interaction with the environment.

\section{Review of Literature}

An experimental study was conducted on 60 mothers to assess the effectiveness of structured teaching programme on knowledge and practice of breast feeding to primi postnatal mothers of Sir Ivan Stedeford hospital, Chennai. Results showed that the overall mean score of the experimental group was 52.14 in the pretest and 77.38 in the post test, where as for the control group the overall mean score was 50.48 in the pretest and only 54.19 in the post test $(p=\varangle 0.001){ }^{5}$

A randomized controlled trial on 200 women on early initiation of oral feeding after cesarean section was conducted by Obafemi Awolowo University Teaching Hospital, Nigeria. The results showed that early feeding group had a shorter mean post-operative time interval to bowel sounds, passage of flatus and bowel movement $(p<$ 0.001 ). Early feeding group had a shorter mean hospital stay and required less intravenous fluid $(p<0.001)$. The study concludes that early feeding after caesarean section was well tolerated and safe and can be implemented without an increase in adverse outcome. ${ }^{6}$

A quasi experimental study was conducted on 80 primi mothers on the effectiveness of planned teaching programme regarding self perineal toileting after delivery in a selected hospital, AndhraPradesh. The results showed that the mean gain level of knowledge between pre and post test in experimental group was 39.89 and that in 
control group was 0.09.The calculated $t$ value is 23.6 $(\mathrm{P}<0.001)$ shows that there is a significant increase in the level of knowledge in the experimental group than the control group. The researcher concluded that planned teaching is effective in promoting the knowledge on self perineal care after delivery. ${ }^{7}$

\section{Methodology:}

One group pre test post test design which is a pre experimental research design was adopted.

\section{Sample}

40 mothers undergoing elective caesarean section at selected hospitals in Mangalore and who satisfied the inclusion criteria were included as samples.

\section{Data Collection Process}

Pre-test was administered to the mothers two days prior to caesarean section on knowledge of post operative self care after caesarean section using structured knowledge questionnaire. The researcher collected the demographic data along with this. It took approximately 30 minutes. After pre test researcher distributed the self instructional module on post operative self care to the mothers. After 5 days of intervention, the researcher administered the post test to assess the level of knowledge of mothers using the same structured knowledge questionnaire.

\section{Results:}

The collected data were analyzed by using descriptive and inferential statistics. The findings revealed that highest percentage $(42.5 \%)$ of mothers were in the age group of 21 -25 years. Majority of the mothers (45\%) were Muslims. Many of the them $(52.5 \%)$ were primigravida mothers.

\section{References:}

1. Orshman AS. Maternity Newborn and Women's Health Nursing. $1^{\text {st }}$ edition. Philadelphia: Lippincott Williams and Wilkins publishers; 2008.

2. Fraser DM , Cooper MA, Fletcher G. M yles Textbook of M idwives. $14^{\text {th }}$ edition. Philadelphia: Churchill Livingstone, 2003.

3. Lowdermilk LD, Perry ES. Maternity and Woman's Health Care $8^{\text {th }}$ edition. M issouri: M osby Publishers; 2004.

4. http://www.who.int/reproductive_health/index.htm(20-10-08)
Most of the mothers (35\%) completed high school education. Majority of the mothers (75\%) were housewives. Majority of the mothers ( $80 \%$ ) had monthly income between Rs.3001 - Rs.10, 000. Most (52.5\%) of them had no exposure to any of the health awareness. Many of the mothers $(52.5 \%)$ had history of previous caesarean section.

The data showed that out of 40 mothers maximum number of mothers $24(60 \%)$ had average knowledge. The mean knowledge score was 14.98 whereas maximum possible score was 30. Among the eleven areas, the mean percentage knowledge score in the area of caesarean section and self care was $77.50 \%$, bladder and bowel care was $60 \%$, breast feeding was $58.40 \%$, diet was $52.50 \%$, pain management was $47.50 \%$, post operative complications and home care was $46 \%$, baby care was $44.33 \%$, early ambulation and exercises was $44 \%$, perineal hygiene was $41 \%$, wound care was $40.67 \%$ and deep breathing and coughing was $40.67 \%$.

There was significant difference found between the mean pre test knowledge score and mean post test knowledge score,('t' calculated value of pretest and post test knowledge scores $=18.000, p \varangle 0.001$ ) which showed that self instructional module was effective in improving the knowledge of mothers on post operative self care after caesarean section.

There was significant association between the level of knowledge and demographic variables namely age, parity, education, occupation, monthly income, exposure to health awareness, and history of caesarean section.

5. Vijaya SS, M enon AV, Breast feeding teaching for better practice. The Nursing J ournal of India 2002, Aug; LXXXXIII (8):173-75.

6. Orji EO, Olabode TO, Kuti O, Ogunniyi SO. A randomized controlled trial of early initiation of oral feeding after caesarean section J M atern Fetal Neonatal M ed 2009 Jan; 22(1):65-71.

7. Yasoda. Effectiveness of planned teaching programme on self perineal toileting in postnatal mothers. Indian Journal of Nursing and midwifery $2002 \mathrm{M}$ ar; $70(1): 34-5$. 